\title{
Intestinal parasitic infections and determinant factors among school-age children in Ethiopia: a cross-sectional study
}

\author{
Awrajaw Dessie ${ }^{1 *} \mathbb{D}$, Tesfay Gebregzabher Gebrehiwot ${ }^{2}$, Berihu Kiros ${ }^{2}$, Sintayehu Daba Wami ${ }^{1}$ \\ and Daniel Haile Chercos
}

\begin{abstract}
Objective: This study aimed to determine the prevalence of intestinal parasitic infections and associated factors among school-age children in Sebeya primary school, northern Ethiopia, 2017.

Results: The prevalence of intestinal parasites in school-age children was (29.9\%). A total of six parasites were detected in this study. E. histolytica/dispar 19.43\% (82/422) and G. lamblia 8.29\% (35/422) were the predominant ones. Unclean fingernail ( $A O R=1.72)$, defecating in the open field $(A O R=2.82)$, and being barefooted $(A O R=1.72)$ were the determinant factors for intestinal parasitic infections. Frequently washing hands reduced the chance of infections by $68 \%$. Furthermore, children in grade $1-4$ and $5-6$ had higher odds developing the infections than those in grade $7-8$ ( $A O R=8.21$ and $A O R=2.50$, respectively).
\end{abstract}

Keywords: Intestinal parasitic infections, Children, Prevalence, Polyparasitism, School

\section{Introduction}

Helminths and protozoa species, causing intestinal parasitic infections, are endemic worldwide. It is considered the pressing public health issues, predominantly in tropical and subtropical countries. About 3.5 billion individuals are impacted, of which and 450 million people suffering from the diseases [1]. In resource limited parts of the world, the problem of intestinal parasite diseases is deep [2]. The intestinal parasites are extremely common in crowded or unhealthy circumstances such as refuse heaps, gutters and wastewater units in and around people's dwelling and living circumstances [3].

Children are disproportionately at risk for the infections, amongst others, owing to their increased nutritional requirements and less developed immune systems [4]. Intestinal parasite diseases linked with intestinal bleeding, nutrient malabsorption, nutrient deficiency, and cell and tissue destruction, anemia, intestinal

\footnotetext{
*Correspondence: awrajawdss@gmail.com

1 Department of Environmental and Occupational Health and Safety, Institute of Public Health, University of Gondar, Gondar, Ethiopia

Full list of author information is available at the end of the article
}

obstruction, and mental and physical development retardation among children. Overall, these results in delayed growth, decreased mental development, school absenteeism, low academic achievement, prone to malnutrition and infection [5-7].

In Ethiopia, infections with intestinal parasites are toping the morbidity list in different health facilities. A. lumbricoides, T. trichiura, $H$. nana, histolytica/dispar, and $S$. mansoni are highly spread in the country [8-11]. There are, however, still several locations for which epidemiological data, including the research region, is not accessible. Poor environmental and personal hygiene, food contamination, unsafe drinking water, and improper management of urine and faeces led to the occurrence of the infection [12]. Poverty, analphabetism, bad sanitation, water inaccessibility, and warm and humid tropical climate have also been correlated with parasitic intestinal diseases in Ethiopia [10].

Determining the status of intestinal parasitic diseases and its correlates is crucial not only to formulate appropriate control strategies but also to envisage the risk to considered groups. Existing knowledge indicated the problem is differing from location to location based on 
the different variables enlisted in Ethiopia and there is scanty of information in the study area. This study, therefore, aimed to determine the prevalence and risk factors of intestinal parasites among schoolchildren in Northern Ethiopia.

\section{Main text \\ Methods \\ Study setting and period}

The study was conducted in Sebeya primary school from January to February 2017. It is located in Glomekeda district, northern Ethiopia, which $915 \mathrm{~km}$ far from Addis Ababa, the capital city of Ethiopia. The school is located in altitude of $2528 \mathrm{~m}$ above sea level and geographically it is located $14^{\circ} 28^{\prime} 14.15^{\prime \prime} \mathrm{N}$ latitude and $39^{\circ} 29^{\prime} 40.5^{\prime \prime} \mathrm{E}$ longitude.

\section{Study design}

Institution based cross-sectional study was employed.

\section{Study population}

School-age children from grade 1 to 8 who were available during the period of data collection, whose parents/ guardians have given assent and who agreed to participate were included.

\section{Sample size determination and sampling technique}

The sample size was determined using a single population proportion formula, considering the proportion of intestinal parasitic infection $47.1 \%$ [13], a margin of error $5 \%$, confidence interval of $95 \%$, as assumptions. The final sample size was 422 including a $10 \%$ non-response rate students. Samples were selected by simple random sampling technique. Proportional allocation was made to select the study subjects from each grade level based on the number of students at each grade level.

\section{Operational definitions}

Intestinal parasitic infection (IPS): The participant was recorded positive for IPs if the stool sample examined by microscopy becomes positive to cyst or trophozoite of any parasite.

Washing hands at critical times: Washing hands after visiting the toilet, before a meal, after touching the bottom of the child, after touching animal pets, before food preparation.

Knowledge: Participants were asked to answer 10 knowledge questions about transmission and prevention methods of intestinal parasitic infection. Graded as having "Good knowledge" if they had answered correctly ( $\geq 80 \%$ ) 8-10 questions, medium if they had answered
(50-70\%) 5-7 questions, and $<5$ questions as "Poor knowledge".

\section{Data collection tools and procedure}

To collect appropriate data from each student, a structured questionnaire was prepared. Parents and guardians of the chosen learners were traced and interviewed for socio-demographic variables, environmental factors, and hygienic behavior. Meanwhile, data collectors verified the accessibility of the bathroom and the fingernail cleanliness of each student.

\section{Stool sample collection and processing}

Two gram of new fecal samples were gathered from children and put in separately labeled containers of smooth plastic stools. The nature of the stool sample was observed and the date of sampling was also noted. The specimens were preserved with $10 \%$ formalin and transported to the Mekelle University Medical Parasitology Laboratory. To identify parasitic organisms, a method of formol-ether concentration was employed as described by the standard method [14].

\section{Quality control}

Data collectors and supervisors have been trained on the methods of data collection. On the spot checking of the completeness of the data was done. The stool specimen examination was done following standard laboratory procedures and few randomly selected samples were re-checked for verification.

\section{Data processing and analysis}

Data were entered into EPI Info 7 and exported to SPSS 20 for analysis. Mean, frequency and percentage were used for description. A binary logistic regression model was used to identify significantly associated variables at a $p$ value $<0.05$. During bivariate analysis, variables with a $p$-value $<0.2$ were candidates for multivariable logistic regression for the final model. Hosmer and Lemeshow goodness-of-fit test were performed.

\section{Results}

\section{Socio-demographic characteristics}

This research involved a total of 422 school children, which yields $100 \%$ response rate. About 227 (53.79\%) were females. The mean $( \pm \mathrm{SD})$ age of study participants was $11.5( \pm 2.31)$ years. Half of the parents (50.24\%) receive less than 500 ETB of monthly income (Additional file 1: Table S1). 


\section{Environmental and behavioral characteristics}

Two-thirds of children's parents (63.6\%) collected water from well water and 258 (61.1\%) washing their hands at critical moments. Two hundred and forty-three (57.6\%) of children frequently brushed their teeth and $183(43.8 \%)$ clean their fingernail. More than two-thirds of children (65.4\%) always had to wear shoes. Two hundred and thirty-nine (56.6\%) children had little knowledge on prevention and control of intestinal parasite infection (Table 1).

\section{Prevalence of the intestinal parasite infection}

The prevalence of intestinal parasite infection was 29.9\% (95\% CI 27.7-32.1\%). About 31.3\% (61/195)

Table 1 Environmental and behavioral characteristics of Sebeya primary school children, January to February, $2017(n=422)$

\begin{tabular}{|c|c|c|}
\hline Variables & Frequency (n) & Percent (\%) \\
\hline \multicolumn{3}{|l|}{ Type of water source } \\
\hline Pipe & 58 & 13.7 \\
\hline Spring & 96 & 22.7 \\
\hline Hand dug well & 268 & 63.6 \\
\hline \multicolumn{3}{|l|}{ Open field defecation } \\
\hline Yes & 35 & 8.3 \\
\hline No & 387 & 91.7 \\
\hline \multicolumn{3}{|c|}{ Washing hands at critical times } \\
\hline Yes & 258 & 61.1 \\
\hline No & 164 & 38.9 \\
\hline \multicolumn{3}{|c|}{ Frequency of taking bath } \\
\hline Once a week & 84 & 19.9 \\
\hline Once in a month & 61 & 14.5 \\
\hline Twice a month & 277 & 65.6 \\
\hline \multicolumn{3}{|l|}{ Brushing teeth regularly } \\
\hline Yes & 243 & 57.6 \\
\hline No & 179 & 42.4 \\
\hline \multicolumn{3}{|c|}{ Frequency of washing cloth } \\
\hline Once a week & 42 & 10.0 \\
\hline Twice a month & 134 & 31.8 \\
\hline Once a month & 246 & 58.2 \\
\hline \multicolumn{3}{|l|}{ Clean finger nail } \\
\hline Yes & 185 & 43.8 \\
\hline No & 237 & 56.2 \\
\hline \multicolumn{3}{|l|}{ Shoe wearing habit } \\
\hline Regular & 276 & 65.4 \\
\hline Irregular & 146 & 34.6 \\
\hline \multicolumn{3}{|l|}{ Knowledge } \\
\hline Knowledgeable & 103 & 24.4 \\
\hline Not knowledgeable & 319 & 75.6 \\
\hline
\end{tabular}

of males were infected with at least one parasite and $28.6 \%(65 / 227)$ of females had the infection. The rate of single, double, and triple parasite infections was $73.02 \%$ (92/126), 20.63\% (26/126), and 6.35\% (8/126), respectively. A total of six parasites were detected and $E$. histolytica/dispar 19.43\% (82/422) and G. lamblia $8.29 \%$ (35/422) were the predominant ones (Table 2).

\section{Factors associated with intestinal parasitic infection}

In multivariable analysis; grade level, father occupation, clean fingernail, open field defecation, hand washing at critical times, and shoe wearing habit were discovered to be statistically associated with parasitic intestinal diseases (p-value < 0.05) (Table 3).

According to this study, children in grade $1-4$ and 5-6 were 8.21 and 2.5 times more likely than their counterparts to have intestinal parasitic diseases $[\mathrm{AOR}=8.21$, $95 \%$ CI 3.88, 17.47, and AOR $=2.50,95 \%$ CI 1.14, 5.54]. Children whose father's work was a daily worker were 2.96 times more likely than children whose father's job was a civil servant to develop intestinal parasitic diseases [AOR $=2.96,95 \%$ CI 1.07, 8.18].

Children with unclean fingernails were 1.72 times more probable than children with clean fingernails to develop parasitic intestinal infections $[\mathrm{AOR}=1.72,95 \%$ CI 1.04 , $2.85]$. On the other side, children who were washing hands at critical moments were $68 \%$ less probable than their counterparts to develop intestinal parasite infection $[\mathrm{AOR}=0.32,95 \% \mathrm{CI} 0.16,0.65]$. Children who defecate in the open field were 2.82 times higher odds of developing intestinal parasite infections compared to children who did not practice open field defecation $[\mathrm{AOR}=2.82$, 95\% CI 1.21, 7.45]. Besides, the prevalence of intestinal parasite diseases was $72 \%$ greater in children with uneven shoe habit $[\mathrm{AOR}=1.72,95 \%$ CI 1.02, 2.91].

\section{Discussion}

The purpose of this research was to evaluate the prevalence of parasitic intestinal diseases among school-age children. In the current research, the prevalence of intestinal parasite diseases was discovered to be $29.9 \%$. This finding is comparable with other studies that reported $27.2 \%$ in Babile [9], and 29.3\% in Mekelle [15]. On the other hand, the prevalence was greater than the study conducted in Tilili, Ethiopia, which was reported to be 26.2\% [11], and in Butajira, Ethiopia, which was 23.3\% [16]. To the contrary, higher prevalence of intestinal parasites disease was found from 58 to $83.8 \%$ in different towns of Ethiopia [17-20]. Similarly, a higher prevalence of the disease compared to the current finding was reported in sub-Saharan Africa; e.g. 48.7\% in Tanzania [23], and 90.4\% in Central Sudan [24]. The distinction in parasitological diagnostic techniques used, level of 
Table 2 Distribution of intestinal parasites species among Sebeya primary school children, January to February, 2017 $(n=422)$

\begin{tabular}{|c|c|c|c|}
\hline Type of intestinal parasite & Number of male +ve (\%) & Number of female + ve (\%) & $\begin{array}{l}\text { Total number } \\
\text { of + ve (\%) }\end{array}$ \\
\hline \multicolumn{4}{|l|}{ Single infection $(n=92)$} \\
\hline E. histolytica/dispar & $26(6.2)$ & $24(5.7)$ & $50(11.8)$ \\
\hline G. lamblia & $8(1.9)$ & $12(2.8)$ & $20(4.7)$ \\
\hline A. lumbricoides & $8(1.9)$ & $6(1.4)$ & $14(3.3)$ \\
\hline H. nana & $2(0.5)$ & $1(0.2)$ & $3(0.7)$ \\
\hline Hookworm & $1(0.2)$ & $2(0.5)$ & $3(0.7)$ \\
\hline T. trichiura & $1(0.2)$ & $1(0.2)$ & $2(0.5)$ \\
\hline \multicolumn{4}{|l|}{ Double infection $(n=26)$} \\
\hline E. histolytica/dispar and G.lamblia & $6(1.4)$ & $4(0.9)$ & $10(2.4)$ \\
\hline E. histolytica/dispar and A. lumbricoides & $4(0.9)$ & $3(0.7)$ & $7(1.7)$ \\
\hline E. histolytica/dispar and H. nana & $2(0.5)$ & $5(1.2)$ & $7(1.7)$ \\
\hline G. lamblia and A. lumbricoides & $0(0.0)$ & $2(0.5)$ & $2(0.5)$ \\
\hline \multicolumn{4}{|l|}{ Triple infection $(n=8)$} \\
\hline E. histolytica/dispar, G. lamblia and H. nana & $2(0.5)$ & $1(0.2)$ & $3(0.7)$ \\
\hline E. histolytica/dispar, H. nana and Hookworm & $0(0.0)$ & $3(0.7)$ & $3(0.7)$ \\
\hline E. histolytica/dispar, Hookworm and T. trichiura & $1(0.2)$ & $1(0.2)$ & $2(0.5)$ \\
\hline Total & $61(14.5)$ & $65(15.4)$ & $126(29.9)$ \\
\hline
\end{tabular}

Table 3 Multivariate analysis for factors potentially associated with Intestinal parasite infection among Sebeya school children, January to February, 2017

\begin{tabular}{|c|c|c|c|c|}
\hline \multirow[t]{2}{*}{ Risk factor } & \multicolumn{2}{|c|}{ Status of intestinal parasitic infections } & \multirow[t]{2}{*}{ COR $(95 \% \mathrm{Cl})$} & \multirow[t]{2}{*}{ AOR $(95 \% \mathrm{Cl})$} \\
\hline & Positive, n (\%) & Negative, $n(\%)$ & & \\
\hline \multicolumn{5}{|l|}{ Grade level } \\
\hline $1-4$ & $90(50.6)$ & $88(49.4)$ & $9.29(4.78,18.06)^{* *}$ & $8.21(3.88,17.48)^{* *}$ \\
\hline $5-6$ & $24(19.5)$ & $99(80.5)$ & $2.20(1.05,4.64)^{* *}$ & $2.51(1.14,5.540)^{*}$ \\
\hline $7-8$ & $12(9.9)$ & $109(90.1)$ & 1.00 & 1.00 \\
\hline \multicolumn{5}{|c|}{ Father occupation } \\
\hline Farmer & $88(28.5)$ & $221(71.5)$ & $1.25(0.66,2.35)$ & $1.26(0.62,2.53)$ \\
\hline Daily labourer & $16(51.6)$ & $15(48.4)$ & $3.34(1.34,8.33)^{* *}$ & $2.96(1.07,8.18)^{*}$ \\
\hline Trader & $7(35.0)$ & $13(65.0)$ & $1.69(0.57,5.00)$ & $1.28(0.38,4.22)$ \\
\hline Civil servant & $15(24.2)$ & $47(75.8)$ & 1.00 & 1.00 \\
\hline \multicolumn{5}{|l|}{ Clean finger nail } \\
\hline Yes & $43(23.2)$ & $142(76.8)$ & 1.00 & 1.00 \\
\hline No & $83(35.0)$ & $154(65.0)$ & $1.78(1.15,2.74)^{* *}$ & $1.72(1.04,2.85)^{* *}$ \\
\hline \multicolumn{5}{|c|}{ Open field defecation } \\
\hline Yes & $21(60.0)$ & $14(40.0)$ & $4.03(1.98,8.21)^{* *}$ & $2.82(1.21,7.45)^{* *}$ \\
\hline No & $105(27.1)$ & $282(72.9)$ & 1.00 & 1.00 \\
\hline \multicolumn{5}{|c|}{ Washing hands at critical times } \\
\hline Yes & $71(27.5)$ & $187(72.5)$ & $0.45(0.29,0.69)^{* *}$ & $0.32(0.16,0.65)^{*}$ \\
\hline No & $55(33.5)$ & $109(66.5)$ & 1.00 & 1.00 \\
\hline \multicolumn{5}{|c|}{ Shoe wearing habit } \\
\hline Regular & $57(31.5)$ & $124(68.5)$ & 1.00 & 1.00 \\
\hline Irregular & $82(32.3)$ & $172(67.7)$ & $3.44(2.22,5.33)^{* *}$ & $1.72(1.02,2.91)^{* *}$ \\
\hline
\end{tabular}

$1.00=$ Reference, ${ }^{*}$ significant at $\mathrm{p}$ value $<0.05,{ }^{* *}$ significant at $\mathrm{p}$ value $<0.001$ 
environmental sanitation, source of drinking water, family education and personal hygiene may be correlated with the discrepancy [21].

Grade level of school children was found to be a significant predictor of intestinal parasitic infections; lower-grade school children had higher probability of developing the infections when compared to their counterparts. Children of lesser grade tend to play in the open field and generally touch their mouth with their dirty fingers may explain the result. Their understanding of disease prevention and control mechanisms could be small, further predisposing to diseases with parasites. The finding is consistent with comparable research in Ethiopia showing that children in lower grade had a greater prevalence of intestinal parasite diseases [22, 23].

Interventions in public health including access to safely managed drinking water, community health education, food hygiene, functional sanitation systems are key for long-term intestinal parasite control [21, 24-26]. In this research, the main modifiable predictors' hygiene behavior such as the cleanliness of fingernail and not handwashing, and open defecation. Chances of infection with intestinal parasites have risen by $72 \%$ among children with unclean fingernails compared to children with smooth fingernails, which is consistent with other research [21, 23, 27, 28]. Because the fecal-oral path is the primary pathway for the spread of parasite diseases, unclean fingernails can increase the incidence and intensity of intestinal parasite diseases [27]. Because their habitat is unclean fingers, the life-cycle of soil-borne intestinal parasites can cause direct feco-oral transmission of intestinal parasites.

This research showed that the risk of intestinal parasite infection among children who commonly washed their hands at critical moments was lowered by $68 \%$ compared to children who did not wash. This finding is comparable with the study conducted in different parts of Ethiopian [21, 23, 27]. This can be because children get germs when they touch infected items, which increases the probability of disease. Hand washing is, therefore, the most efficient way to prevent infection from spreading $[27,29,30]$. Similarly, among children who used protective shoes irregularly compared to their counterparts, the chance of affected by intestinal parasite infections increased by $72 \%$. The finding is in agreement with comparable research in developing nations $[17,21,28]$. Possible explanations of shoe-wearing habit link and enhanced infection with parasites may be due to enhanced potential for infection with hookworm. Lack of protective shoes is known to boost the likelihood of infection with hookworms [21].

This study revealed that there was a higher probability of parasite illnesses among children defecating in the open field. This was in agreement with other studies [31, 32]. The possible explanation might be improper management of human feaces led to disease-causing pathogens, particularly infectious eggs and helminth larvae would litter the atmosphere. As these illnesses are transferred through the fecal-oral route or direct skin penetration, the risk of infection with such environmental contamination will increase $[25,26]$.

\section{Conclusion}

In the studied area, the prevalence of intestinal parasite diseases among school-age children was high. Infection with polyparasitism was also a concern. Improving socioeconomic status, enhancing sanitation services, instilling health education and encouraging methods to maintain personal hygiene, constantly developing shoe habit can be excellent strategies for controlling these infections in the region. It is suggested to create a school-based understanding of how intestinal parasites are transmitted.

\section{Limitations}

The study's main limitation was that we did not measure the intensity of the parasite infection, which might better illustrate the degree of infection in the study area. Due to the lack of laboratory equipment, opportunistic infections were not evaluated.

\section{Supplementary information}

Supplementary information accompanies this paper at https://doi. org/10.1186/s13104-019-4759-1.

Additional file 1: Table S1. Socio demographic characteristics of Sebeya primary school children, January to February, 2017 ( $n=422)$.

Abbreviations

AOR: adjusted odds ratio; Cl: confidence interval; COR: crude odds ratio; SD: standard deviation; SPSS: statistical package for social sciences.

\section{Acknowledgements}

The authors are pleased to acknowledge the data collectors, field supervisors, study participants, laboratory technologists, Glomekeda District Health Office, Sebeya Primary School principal, Tigray Regional Health Bureau for their unreserved contributions to the success of this study. The authors would also like to extend their gratitude to the Glomekeda District administrators for their facilitation.

\section{Authors' contributions}

All the authors actively participated during the conception of the research issue, development of a research proposal, data collection, analysis and interpretation, and writing various parts of the research report. AD, TGG and BK had designed the study protocol and had supervised the quality of data, analyzed the data and had written the manuscript. SDW and DHC had analyzed the data and had written the manuscript. All authors read and approved the final manuscript.

\section{Funding}

Not applicable. 


\section{Availability of data and materials}

Data will be made available upon request the primary author

\section{Ethics approval and consent to participate}

The study was conducted after approval of the project by an ethical review committee of college of health science, Mekelle University. Students were involved in the study after receiving written informed consent from their family/guardians and school principal. Children positive for intestinal parasitic infection were treated free of charge and brief health education is given.

\section{Consent for publication}

This manuscript does not contain any person's data.

\section{Competing interests}

The authors declare that they have no competing interests.

\section{Author details}

${ }^{1}$ Department of Environmental and Occupational Health and Safety, Institute of Public Health, University of Gondar, Gondar, Ethiopia. ${ }^{2}$ School of Public Health, College of Health Science, Mekelle University, Mekelle, Ethiopia.

\section{Received: 7 August 2019 Accepted: 24 October 2019}

\section{Published online: 28 November 2019}

\section{References}

1. Okyay P, Ertug S, Gultekin B, Onen O, Beser E. Intestinal parasites prevalence and related factors in school children, a western city sample-Turkey. BMC Public Health. 2004;4(1):1.

2. Mahfouz AA, El-Morshedy H, Farghaly A, Khalil A. Ecological determinants of intestinal parasitic infections among pre-school children in an urban squatter settlement of Egypt. J Trop Pediatr. 1997;43(6):341-4.

3. Korkes F, Kumagai FU, Belfort RN, Szejnfeld D, Abud TG, Kleinman A, et al. Relationship between intestinal parasitic infection in children and soil contamination in an urban slum. J Trop Pediatr. 2008;55(1):42-5.

4. Awasthi S, Bundy DA, Savioli L. Helminthic infections. BMJ. 2003:327(7412):431-3.

5. Dickson R, Awasthi S, Williamson P, Demellweek C, Garner P. Effects of treatment for intestinal helminth infection on growth and cognitive performance in children: systematic review of randomised trials. BMJ. 2000:320(7251):1697-701.

6. Taylor-Robinson DC, Maayan N, Soares-Weiser K, Donegan S, Garner P. Deworming drugs for soil-transmitted intestinal worms in children: effects on nutritional indicators, haemoglobin, and school performance. The Cochrane Library. 2015. https://doi.org/10.1002/14651858.CD000371. pub6.

7. Haque R. Human intestinal parasites. J Health Popul Nutr. 2007;25:387-91.

8. Gelaw A, Anagaw B, Nigussie B, Silesh B, Yirga A, Alem M, et al. Prevalence of intestinal parasitic infections and risk factors among schoolchildren at the University of Gondar Community School, Northwest Ethiopia: a crosssectional study. BMC Public Health. 2013;13(1):304

9. Tadesse $\mathrm{G}$. The prevalence of intestinal helminthic infections and associated risk factors among school children in Babile town, eastern Ethiopia. Ethiop J Health Dev. 2005;19(2):140-7.

10. Legesse M, Erko B. Prevalence of intestinal parasites among schoolchildren in a rural area close to the southeast of Lake Langano, Ethiopia. Ethiop J Health Dev. 2004;18(2):116-20.

11. Abera A, Nibret E. Prevalence of gastrointestinal helminthic infections and associated risk factors among schoolchildren in Tilili town, northwest Ethiopia. Asian Pac J Trop Med. 2014;7(7):525-30

12. Organization $\mathrm{WH}$. Prevention and control of intestinal parasitic infections: report of a WHO Expert Committee [meeting held in Geneva from 3 to 7 March 1986]: 1987.

13. Yami A, Mamo Y, Kebede S. Prevalence and predictors of intestinal helminthiasis among school children in Jimma zone; a cross-sectional study. Ethiop J Health Sci. 2011;21(3):167-74
14. Yimer M, Hailu T, Mulu W, Abera B. Evaluation performance of diagnostic methods of intestinal parasitosis in school age children in Ethiopia. BMC Res Notes. 2015:8(1):820.

15. Alemu M, Bedemo H, Bugssa G, Bayissa S, Tedla K. Epidemiology of intestinal parasite infections among kindergarten children in Mekelle Town, Northern Ethiopia. Int J Pharma Sci Res. 2015;6(11):1392-6.

16. Shumbej T, Belay T, Mekonnen Z, Tefera T, Zemene E. Soil-transmitted helminths and associated factors among pre-school children in Butajira Town, South-Central Ethiopia: a community-based cross-sectional study. PLOS ONE. 2015;10(8):e0136342.

17. Sitotaw B, Mekuriaw H, Damtie D. Prevalence of intestinal parasitic infections and associated risk factors among Jawi primary school children, Jawi town, north-west Ethiopia. BMC Infect Dis. 2019;19(1):341.

18. Legesse M, Erko B. Prevalence of intestinal parasites among schoolchildren in a rural area close to the southeast of Lake Langano, Ethiopia. Ethiop J Health Dev. 2004;18(116):120.

19. Mengistu A, Gebre-Selassie S, Kassa T. Prevalence of intestinal parasitic infections among urban dwellers in southwest Ethiopia. Ethiop J Health Dev. 2007;21(1):12-7

20. Workneh T, Esmae A, Ayichiluhm M. Prevalence of intestinal parasitic infections and associated factors among Debre Elias primary schools children, East Gojjam Zone, Amhara Region, North West Ethiopia. J Bacteriol Parasitol. 2014;5(1).https://doi.org/10.4172/2155-9597.1000181

21. Hailegebriel T. Prevalence of intestinal parasitic infections and associated risk factors among students at Dona Berber primary school, Bahir Dar, Ethiopia. BMC Infect Dis. 2017;17(1):362.

22. Tefera E, Mohammed J, Mitiku H. Intestinal helminthic infections among elementary students of Babile town, eastern Ethiopia. Pan African Med J. 2015;20(1):50.

23. Fentahun AA, Asrat A, Bitew A, Mulat S. Intestinal parasitic infections and associated factors among mentally disabled and non-disabled primary school students, Bahir Dar, Amhara regional state, Ethiopia, 2018: a comparative cross-sectional study. BMC Infect Dis. 2019;19(1):549.

24. Anuar TS, Al-Mekhlafi HM, Ghani MKA, Osman E, Yasin AM, Nordin A, et al. Prevalence and risk factors associated with Entamoeba histolytica/dispar/ moshkovskii infection among three Orang Asli ethnic groups in Malaysia. PLOS ONE. 2012;7(10):e48165

25. Mara D, Lane J, Scott B, Trouba D. Sanitation and health. PLoS Med. 2010;7(11):e1000363

26. Lewin S, Norman R, Nannan N, Thomas E, Bradshaw D, Collaboration SACRA. Estimating the burden of disease attributable to unsafe water and lack of sanitation and hygiene in South Africa in 2000. South Afr Med J. 2007;97(8):755-62.

27. Mahmud MA, Spigt M, Bezabih AM, Pavon IL, Dinant G-J, Velasco RB. Efficacy of handwashing with soap and nail clipping on intestinal parasitic infections in school-aged children: a factorial cluster randomized controlled trial. PLoS Med. 2015;12(6):e1001837.

28. Alamir M, Awoke W, Feleke A. Intestinal parasites infection and associated factors among school children in Dagi primary school, Amhara National Regional State, Ethiopia. Health. 2013;5(10):1697.

29. Bloomfield SF, Aiello AE, Cookson B, O'boyle C, Larson EL. The effectiveness of hand hygiene procedures in reducing the risks of infections in home and community settings including handwashing and alcoholbased hand sanitizers. Am J Infect Control. 2007;35(10):S27-64.

30. Haas JP. Handwashing and nail clipping reduce risk of intestinal parasite infection in school-age children. Evid Based Nurs. 2016;19(2):49.

31. Ayalew A, Debebe T, Worku A. Prevalence and risk factors of intestinal parasites among Delgi school children, North Gondar, Ethiopia. J Parasitol Vector Biol. 2011;3(5):75-81.

32. Asemahagn MA. Parasitic infection and associated factors among the primary school children in Motta town, western Amhara, Ethiopia. Am J Pub Health. 2014:2:248-54.

\section{Publisher's Note}

Springer Nature remains neutral with regard to jurisdictional claims in published maps and institutional affiliations. 